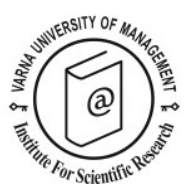

\title{
Schools of thoughts in heritage and tourism management of the historic city
}

\author{
Daniel Barrera-Fernandez ${ }^{1}$
}

Received: 09/03/2015

\begin{abstract}
${ }^{1}$ University of Guanajuato, Department of Architecture. Avenida Juarez 77, 36000 Guanajuato, Gto., Mexico; tel: 00521473102 0100; e-mail: daniel.barrera@ugto.mx
\end{abstract}

Supervisors: María Teresa Pérez Cano

Carlos Jesús Rosa Jiménez

Institution awarding the Ph. D. Degree: University of Malaga

Date of defence: 08/04/2014

(c) 2015 Varna University of Management. All rights reserved

Citation: Fernandez, D. (2015) Schools of thoughts in heritage and tourism management of the historic city. Doctoral Dissertation Summary. European Journal of Tourism Research 11, pp. 162165

\section{Goal and objectives of the dissertation Goal}

The goal of the doctoral thesis is to analyze the tourist use of the historic city and how this process affects to urban heritage in two cities from the British and Mediterranean contexts, namely Plymouth and Malaga.

\section{Objectives}

$\checkmark$ To analyse common and different aspects in heritage preservation and management in Europe, focusing on the British and Spanish models.

$\checkmark$ To examine how the heritage framework has evolved in selected cases and which is the current framework in relation to legislation and the role of administrations involved.

$\checkmark$ To study the historic evolution of urban tourism in both cities and the current relevance of tourism-related activities. $\checkmark$ To analyse the different stakeholders and initiatives affecting the tourist use of the historic city in both cases, dividing them into four aspects: heritage and culture, tourism, urban planning and economy.

$\checkmark \quad$ To compare how both cities compete in bidding for major events, regenerating their waterfront and developing creative neighbourhoods.

$\checkmark$ To develop strategies and proposals to achieve a better balance in the tourist use of Malaga's historic city.

\section{Methodology}

The general work plan is based on Brito's diagram (2009) for approaching the concept of the tourist-historic city (Ashworth and Tunbridge, 2000). It consists of analysis of the historic city as a heritage asset, study of the urban cultural tourism phenomenon and work 
on the definition and management of the tourist-historic city.

The analysis of the British and Spanish models has been made comparing the conceptualisation of heritage, legal framework, weight of the public, private and third sectors, distribution of duties among public agencies, funding and listing process.

Each study case follows the same process as the theoretical framework. At first, the evolution of heritage preservation and management is analyzed since late $19^{\text {th }}$ century until the first decade of $21^{\text {st }}$ century through a qualitative research based on documents from public archives, urban plans and other administrative documents. The current framework is a comparative analysis on designation of protected historic sectors, national and local listing, heritage at risk, evolution of listing criteria and comparison with other cities from the region.

The evolution of urban tourism is based on documents from public archives, urban plans and other administrative documents. There is a specific section for the evolution of references appearing in guidebooks from 1820 to 1990 , following the methodology of Marine-Roig (2011) and Galí Espelt (2005). References have been given a specific value and grouped in 12 thematic categories that reflect the evolution on the interest to visit the selected cities. This methodology has been applied to analyze current guidebooks and other sources of information for tourists as well, making it possible to compare present and past main tourist attractions and services.

The current impact of tourism-related activities is based on the definition of the tourist system made by De la Calle Vaquero (2006). Data has been collected from fieldwork, leaflets, webpages, routes, current guidebooks, direction signs, panels and plaques. References have been given a specific value and grouped in categories. Information has been processed using a virtual cartography tool, following the methodology of Salerno, Casonato and Villa
(2011) and Olukole and Balogun (2011) and finally presented in 13 intensity maps.

The study of stakeholders and initiatives on policies affecting management of tourist use in the historic city is based on fieldwork and qualitative analysis of plans and projects from the public administration, public-private agencies, private companies and third sector organisations.

\section{Results}

In an area of the same size, there are 327 listed assets in Plymouth, while in Malaga there are only 45 . This figure shows the different conceptualisation of heritage in both countries and the distribution of roles between stakeholders. In Plymouth, there is a long tradition of civic initiatives since the creation of Plymouth Barbican Trust, which owns and manages a relevant amount of historic properties in the most visited sector of the city. In Malaga, there is a significant trend to reduce built heritage to a few aesthetic elements in tourist routes, while outside these areas dereliction prevails.

Regarding the tourist use of heritage, a great amount of resources remain underused in Plymouth. There is a coherence of the city's association with seafarers, kept since first guidebooks were issued and updated nowadays to global expectations. In Malaga, the theming process in the tourist core trying to evidence the relationship of the city with Picasso tends to underestimate other resources. Regarding tourist initiatives in the waterfront, there is a significant difference between both cities in relation to mix of uses, protected heritage assets, integration of natural and cultural heritage and physical connection to the city.

\section{Theoretical conclusions}

One of the key impacts of urban tourism is the intensification of the process of heritage selection, resulting in the lack of interest in the less commercial assets. Another impact is the homogeneisation of tourist-historic cities, involving the theming of the most visited streets and losing mix of residents and activities. 
After comparing the British and Spanish models, it is possible to observe a significant difference on the values given to built heritage, while identity prevails in the British model, historic-artistic features are more relevant in the Spanish one. This difference affects heritage management in aspects such as listing criteria, control of heritage at risk, social involvement, ownership and funding for preservation.

When studying actors and initiatives involved in management of the tourist-historic city, the most relevant contribution of the doctoral thesis is the inclusion of the economic dimension to the explained methodology, widely linked to other factors and necessary to achieve sustainability.

\section{Practical application of the dissertation}

Proposals have been presented with the aim of achieving a better balance in the tourist use of Malaga's historic city. The first one is a Plan of Activities to limit concentration of large scale hotels, restaurants and catering facilities in overused streets. Creative activities can be concentrated in the area of Pozos Dulces-Beatas, which has already shown a potential for this segment. A Business Improvement District can be developed to achieve a better balance between costs and benefits. Three new conservation areas can be created. Finally, a Cultural Heritage Integral Management Plan can be useful to join tourist strategies, cultural policies, urban planning, economic delivery, social regeneration and marketing.

\section{Content of the dissertation}

\section{Abstract of chapter one}

In the first chapter a review is made of the international agreements on the definition, heritage values and tourist use of the historic city. It is followed by an approach to urban cultural tourism in aspects such as definition, segmentation, tourists profile, motivations, activities undertaken, visitors' figures and reasons for their rise. Right after, the research focuses on implications of tourism as a regeneration tool in historic urban areas, and the proposals towards a more sustainable model. A specific section is dedicated to the regeneration of the waterfront. After that, the rise of creative tourism and the concentration of creative activities in particular neighbourhoods are treated. Right after, the impact of tourism promotion on city marketing strategies is analyzed, giving attention to the celebration of major events. Below, an approach to the tourist-historic city is made in aspects such as definition, characteristics, special types and actors and policies involved. After that, regional differences in Europe are analyzed, focusing on the British and Spanish models.

\section{Abstract of chapter two}

The second chapter is the case study of Plymouth. Firstly, the evolution of heritage preservation is presented. After that, the current framework studies the designation of conservation areas, statutory listing at a national and local level and heritage at risk. General figures regarding designated assets are presented and compared with other cities. Secondly, the evolution of urban tourism is analyzed, two aspects are treated separately: the achievements of the Plymouth Marketing Bureau and a review of historic guidebooks since the $19^{\text {th }}$ century until the end of the 20th century. The section on the present situation of the tourist sector is divided into four parts: significance of the tourist sector in the city, visitors profile, external and internal accessibility and tourist resources and services. Thirdly, actors and initiatives intervening in the tourist use of the historic city are studied, in relation to culture and heritage, tourism, urban planning and economic development.

\section{Abstract of chapter three}

It is the case study of Malaga and it follows the same structure as Plymouth's one. Taking into account that there is only one conservation area, the analysis of the current framework reflects protected assets inside and outside these boundaries. In the evolution of urban tourism, particular sections have been devoted to the case of the project at Hoyo de Esparteros, the identification with Picasso and a review of historic guidebooks since the $19^{\text {th }}$ century until the end of the 20th century. 


\section{Abstract of chapter four}

In this chapter, local initiatives in relation to three global trends on urban cultural tourism are studied in both cities. Plymouth has bidded for the title of UK City of Culture 2017, while Malaga did the same to be designated European Capital of Culture 2016. The bidding process had an impact on their tourist strategy and heritage-related policies. In both cities significant regeneration strategies are currently underway to increase the tourist interest of the waterfront, thus affecting existing port heritage. Furthermore, both cities have developed a number of initiatives to concentrate creative tourism activities with limited success, showing a common pattern in designing and regenerating those neighbourhoods.

\section{Abstract of chapter five}

It is possible to observe that the transformation of Malaga's historic city to attract a larger amount of visitors has not properly integrated its heritage values. Proposals can be raised from the research about Plymouth and Malaga itself, and from good practices implemented in other cities. Five proposals are explained, which could help Malaga to develop a more sustainable tourist model. They are a Plan of Activities, concentration of creative activities in a neighbourhood that is already showing some potential, a Business Improvement District, modification of the limits of the conservation area and a Cultural Heritage Integral Management Plan.

\section{References:}

Ashworth, G. J., J. E. Tunbridge (2000) The tourist-historic city. Retrospect and the prospect of managing the heritage city. Oxford: Pergamon.

Brito, M. (2009) Ciudades históricas como destinos patrimoniales. Una mirada comparada: España y Brasil. Sevilla: Junta de Andalucía, Consejería de Cultura.

De la Calle Vaquero, M. (2006) La ciudad histórica como destino turístico. Barcelona: Ariel.

Galí Espelt, N. (2005) La imatge turística del patrimoni monumental de Girona. Girona: Universitat de Girona.

Marine-Roig, E. (2011) The image and identity of the Catalan coast as a tourist destination in twentieth-century tourist guidebooks. Journal of Tourism and Cultural Change 9 (2), 118-139.

Olukole, T. O., E. Balogun (2011) Geographical information systems database of cultural heritage resources of Osogbo and their tourism potential. Paper presented at the $\mathrm{IX}^{\text {th }}$ International Forum Le Vie dei Mercanti, $9^{\text {th }}-11^{\text {th }}$ June 2011, Aversa.

Salerno, R., C. Casonato, D. Villa (2011) Sharing heritage: the urban ecomuseum in Milan experiences of participation and new information technologies. Paper presented at the IX ${ }^{\text {th }}$ International Forum Le Vie dei Mercanti, $9^{\text {th }}-11^{\text {th }}$ June 2011, Aversa. 